\title{
Phylogenetic diversity and genotypic complexity of H1N1 subtype swine influenza viruses isolated in Mainland China
}

Yizhi Liu ${ }^{1,2+}$, Jing Wang ${ }^{1,2+}$, Jun $\mathrm{Ji}^{1}$, Shuang Chang ${ }^{3}$, Chunyi Xue ${ }^{4}$, Jingyun Ma ${ }^{1}$, Yingzuo Bi ${ }^{1}$ and Qingmei Xie ${ }^{1^{*}}$

\begin{abstract}
Background: After the occurrence of 2009 pandemic H1N1, close attention has been paid to the H1N1 subtype swine influenza viruses (H1N1 SIV) by scientific communities in many countries. A large-scale sequence analysis of the NCBI Influenza Virus Resource Database on H1N1 SIVs submitted primarily by scientists in China during 1992 to 2011 was performed. The aims of this study were to elucidate the genetic and evolutionary characteristics of H1N1 SIVs, to identify and unify the lineages and genetic characteristics of the H1N1 SIVs isolated in mainland China.

Results: Most of the strains were isolated during the period of 2008 to 2010 from Guangdong and Shandong provinces, China. Based on the phylogenetic and genotypic analyses, all of the H1N1 SIV strains can be classified into 8 lineages and 10 genotypes. All strains were of the characteristics of low pathogenic influenza viruses. The viruses of different lineage are characterized with different amino acid residues at the receptor-binding sites. Viruses containing PB2 genes of the classical swine, early seasonal human and recent seasonal human lineage might be more infectious to human. Some genotypes were directly related with human influenza viruses, which include strains that harbored genes derived from human influenza viruses.

Conclusions: Phylogenetic diversity and complexity existed in H1N1 SIVs isolated in mainland China. These H1N1 SIV strains were closely related to other subtype influenza viruses, especially to human influenza viruses. Moreover, it was shown that, novel lineages and genotypes of H1N1 SIVs emerged recently in mainland China. These findings provided new and essential information for further understanding of the genetic and evolutionary characteristics and monitoring the H1N1 SIVs in mainland China.
\end{abstract}

\section{Background}

Influenza is a very important viral respiratory disease causing outbreaks yearly in tropical and subtropical countries with low morbidity but high mortality and has been posing a threat to economy and public health [1]. Influenza A viruses have been isolated from humans and a number of animals including birds, dogs, seals, horses, and swine [2].

To date, based on hemagglutinin (HA) and neuraminidase (NA) of the two surface glycoproteins [2,3], 16 subtypes of HA and 9 subtypes of NA have been found in influenza A viruses [4-6]. Swine influenza was caused

\footnotetext{
*Correspondence: qmx@scau.edu.cn

${ }^{\dagger}$ Equal contributors

${ }^{1}$ College of Animal Science, South China Agricultural University, Guangzhou 510642, China

Full list of author information is available at the end of the article
}

by influenza A virus firstly isolated in 1930 in North American by Shope [7]. H1N1, H3N2 and H1N2 that include classical swine H1N1, European avian-like H1N1, human-like H3N2, reassortant H3N2, and various genotype H1N2 viruses are the three main subtypes of influenza viruses are circulating in the swine population worldwide [8-11].

Swine influenza viruses cause significant economic losses in animal husbandry, human disease [12], and occasionally give rise to human pandemics [13]. The 2009 pandemic H1N1, a new swine-origin influenza A (H1N1) virus, caused the latest human pandemic $[14,15]$. After the occurrence of the 2009 pandemic H1N1, the virus was repeatedly introduced back into pigs in many countries [16-18].

With the swine influenza virus movement increasing, it raised hardness to predict the evolutionary consequences,

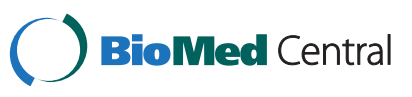


and demand consideration given an increasingly globalized future [19]. It was reported that reconstructing the origins of pandemic have been hampered as a result of lacking systematic and longitudinal influenza surveillance in pigs [13]. Most existing swine data were derived from opportunistic samples collected from diseased pigs in disparate geographical regions, not from prospective studies in defined locations. Hence the evolutionary and transmission dynamics of swine influenza viruses are poorly understood [19].

Since the first isolation of a human influenza virus in 1933, 1957 and 1968 pandemics originated in China [20]. Findings have contributed to the hypothesis that China serves as an epicenter of pandemic influenza viruses throughout history [21]. Since the first report of H1N1 SIVs in China in 1992 [22], several studies of H1N1 SIVs prevalence and genetic have been carried out. China was the biggest pork producer in the world, as the pork industry continued to develop, swine influenza virus became prevalent in mainland China especially in recent years. We performed a large-scale sequence analysis of the NCBI Influenza Virus Resource Database on H1N1 SIVs isolated in mainland China from 1992 to 2011, to comprehensively elucidate the genetic and evolutionary characteristics of H1N1 SIVs in mainland China, and attempt to identify and unify all lineages and genotypes of H1N1 SIVs in mainland China.

\section{Results}

Strains differences based on separation time point and region

In this study, 94 strains and 712 segments of H1N1 SIVs in mainland China (Additional file 1: Table S1) were obtained from the NCBI Influenza Virus Resource Database (http://ncbi.nlm.nih.gov/genomes/FLU/FLU.html) till December 27, 2011.

Reported strains in GenBank were mostly isolated in recent years especially in 2008, 2009, and 2010, in Guangdong and Shandong province (Table 1). As pigs raised in increasing numbers continually in many provinces of mainland China, H1N1 SIVs might become more prevalent in the nation.

\section{Phylogenetic analysis of H1N1 subtype swine influenza viruses in mainland China from 1992 to 2011}

To elucidate the genetic and evolutionary characteristics of H1N1 SIVs in mainland China from 1992 to 2011, the genomes of the viruses were analyzed along with the reference sequences available in GenBank, consisting of viruses isolated from swine, avian, and human. Eight viral gene segments of the viruses were aligned and analyzed phylogenetically.

In the phylogenetic trees of the HA and NA gene of the H1N1 SIVs (Figures 1, 2), it indicated that the HA and NA gene of H1N1 SIVs in mainland China mainly fall into five lineages, the classical swine (CS) lineage, the early seasonal human (ESH) lineage, the recent seasonal human (RSH) lineage, the Eurasian avian-like (EA) lineage, and the 2009 human $(2009 \mathrm{H})$ lineage.

Phylogenetic analyses of the PB2, PA, NP and M gene showed that those could be separated into six major subgroups (Figures 3, 4, 5, 6), including the CS lineage, the North American triple reassortant (TR) lineage, the EA lineage, the $2009 \mathrm{H}$ lineage, the ESH lineage, and the RSH lineage.

A phylogenetic analysis of the NS gene showed that all of the NS genes from these H1N1 SIVs could be divided

Table 1 Regularity of the H1N1 subtype swine influenza viruses in China mainland from 1992 to 2011 in the separation time and region

\begin{tabular}{|c|c|c|c|c|c|c|c|c|c|c|c|c|}
\hline & Total number & Year & & & & & & & & & & \\
\hline & & 1991 & 2001 & 2002 & 2004 & 2005 & 2006 & 2007 & 2008 & 2009 & 2010 & 2011 \\
\hline Beijing & 4 & 2 & & & & & & & 2 & & & \\
\hline Fujian & 3 & & & & & & & 1 & 2 & & & \\
\hline Guangdong & 56 & & 2 & 1 & & 2 & 7 & & 4 & 14 & 26 & \\
\hline Guangxi & 1 & & & & & & & & & & & 1 \\
\hline Henan & 1 & & & & & & 1 & & & & & \\
\hline Hubei & 5 & & & & & & & & & 5 & & \\
\hline Jiangsu & 2 & & & & & & & & & & & 2 \\
\hline Liaoning & 1 & & & & & & 1 & & & & & \\
\hline Nanchang & 4 & & & & & & & & & & 4 & \\
\hline Shandong & 12 & & & & & & & & 9 & 3 & & \\
\hline Shanghai & 3 & & & & & 3 & & & & & & \\
\hline Tianjin & 1 & & & & 1 & & & & & & & \\
\hline Zhejiang & 1 & & & & & & & 1 & & & & \\
\hline
\end{tabular}


Figure 1 Phylogenetic tree of the HA gene of the H1N1 subtype swine influenza viruses. The unrooted phylogenetic trees were generated by the neighbor-joining method using MEGA 5.0 software. Bootstrap values were calculated out of 1000 replicates and only bootstrap values of $\geq 70 \%$ were shown. Different lineages were indicated by different colors.

into seven lineages (Figure 7), respectively, which were the CS lineage, the TR lineage, the EA lineage, the $2009 \mathrm{H}$ lineage, the ESH lineage, the RSH lineage, and the human H3N2 (H3N2H) lineage.

As shown in the phylogenetic tree of the PB1 genes, clear divisions of each of these genes into different lineages exited, including the CS lineage, the TR lineage, the EA lineage, the $2009 \mathrm{H}$ lineage, and the avian H9N2 (H9N2A) lineage (Figure 8).

The detailed analysis of the genetic relationship between H1N1 SIVs and human influenza viruses displayed that the $2009 \mathrm{H}$ lineage and the TR lineage were located in the sister lineage in the phylogenetic trees of the PB2, PB1, PA, NP and NS gene, while the 2009H lineage was in the sister lineage with the EA lineage in the phylogenetic trees of the NA and M genes, similarly with previous research [15]. In the phylogenetic trees of the PB2, $\mathrm{PB} 1, \mathrm{PA}, \mathrm{HA}, \mathrm{NP}$ and M gene, the CS, ESH and the $\mathrm{RSH}$ lineages were in the sister lineage, while the EA lineage was in the sister lineage with the RSH, ESH and $\mathrm{H} 3 \mathrm{~N} 2 \mathrm{H}$ lineages in the phylogenetic tree of the NS gene. The gene segments of REH, ESH, 2009H, and H3N2H lineage derived from recent human influenza viruses, early human influenza viruses, 2009 human pandemic influenza viruses, and human $\mathrm{H} 3 \mathrm{~N} 2$ influenza viruses respectively. And the genes of $\mathrm{H} 9 \mathrm{~N} 2 \mathrm{~A}$ lineage derived from avian H9N2 influenza viruses. Those should be obtained special attention.

Interestingly, through the panorama view of the resulting phylogenetic trees, we found that early human influenza virus genome segments appeared in the CS lineage. And a human influenza virus strain (A/Jiangsu/ALS1/ 2011/H1N1) appeared in the EA phylogenetic tree, indicating that the avian-origin European H1N1 SIVs remain endemic in swine and have retro-infected humans after circulating through swine [23].

These findings further highlighted the phylogenetic diversity and complexity of the H1N1 subtype swine influenza viruses, and showed that H1N1 subtype swine influenza viruses were related to other subtype influenza viruses in mainland China.

\section{Panorama genotypic diversity of H1N1 subtype swine} influenza viruses in mainland China

Taken together, on the basis of the phylogenetic analyses of all eight gene segments of H1N1 SIVs isolated from 
Figure 2 Phylogenetic tree of the NA genes of the H1N1 subtype swine influenza viruses. The unrooted phylogenetic trees were generated by the neighbor-joining method using MEGA 5.0 software. Bootstrap values were calculated out of 1000 replicates and only bootstrap values of $\geq 70 \%$ were shown. Different lineages were indicated by different colors.

pigs in mainland China from 1992 to 2011, the viruses in the present study could be divided into 10 genotypes, which were shown in Figure 9. The genetic composition of the genotypes of CS, EA, 2009H, RSH, and ESH series contained the same segments origin respectively. Of these genotypes CS-H3N2H, EA-H9N2A, EA-TR, 2009H-EA, and TR-EA included the distinct gene sources.

The genotypes of 2009H, ESH, RSH, CS-H3N2H and 2009H-EA were directly related to human influenza viruses, including strains harbored genes derived from human influenza viruses. The eight gene segments of genotype RSH, ESH, and $2009 \mathrm{H}$ derived from recent human influenza viruses, early human influenza viruses, and 2009 human pandemic influenza viruses respectively. Genotype CS-H3N2, such as A/swine/Shandong/ $1123 / 2008 / H 1 N 1$, its NS gene originated from human H3N2 influenza viruses, the remaining segments from the classic swine influenza viruses. NS gene of EA-TR genotype viruses belonged to the North American triple reassortant influenza viruses, with other genes derived from the Eurasian avian-like influenza viruses. Genotype EA-H9N2A represented that virus recombinant PB1 gene from avian influenza viruses, remaining genes originated from the Eurasian avian-like influenza viruses. The $2009 \mathrm{H}$-EA genotype strains appeared to evolve from the Eurasian avian-like influenza viruses by recombinant HA, NA gene, and the internal genes from the 2009 human influenza viruses. HA, M, and NA gene of TREA genotype strains belonged to the Eurasian avian-like influenza viruses, the other genes derived from the North American triple reassortant viruses.

These findings showed that novel genotypes of H1N1 SIVs were existed in mainland China, and further revealed the diversity and complexity of H1N1 SIVs in mainland China.

\section{Key site analyses}

To investigate the characteristics of different lineages (CS, TR, EA, 2009H, ESH, RSH, H3N2H, and H9N2A) of the H1N1 SIVs, the amino acid sequences of the HA and PB2 genes were also aligned (Table 2).

The HA protein was responsible for binding to receptors on host cells and initiating infection, and it was also the principal target of the host's immune system $[2,24,25]$. Molecular analysis of the haemagglutinin gene 
Figure 3 Phylogenetic tree of the PB2 genes of the H1N1 subtype swine influenza viruses. The unrooted phylogenetic trees were generated by the neighbor-joining method using MEGA 5.0 software. Bootstrap values were calculated out of 1000 replicates and only bootstrap values of $\geq 70 \%$ were shown. Different lineages were indicated by different colors.

was essential to monitor the fit to the vaccine strain, as well as variations of the gene that may alter the pathogenicity of circulating virus strains.

Based on the sequence alignment, there were no basic amino acids insertion at the HA cleavage sites. Most of the strains of eight lineages contained an amino acid motif PSIQSR $\downarrow G$ at the HA cleavage sites, which met the characteristic of low pathogenic influenza viruses.

The substitution of aspartic acid (D) to glycine (G) at position 222, D222G (225 in N2 numbering) in HA1 subunit confered viral affinity for $\alpha 2-3 / \alpha 2-6$-linkage specificity,enabling the variant protein to bind to both receptors [26]. Strains belonged to the $20009 \mathrm{H}$ lineage possessed D at the position 222, while CS, ESH, RSH lineage strains possessed G. Interestingly, the EA lineage strains possessed $\mathrm{E}$ or $\mathrm{K}$ at the position 222.

Viruses which contained L226 had a higher affinity for sialic acid $\alpha 2,6$-galactose (SA $\alpha 2,6 \mathrm{Gal})$ and a higher infectivity level for primary swine and human respiratory epithelial cells, whereas viruses contained Q226 had lower SA $\alpha 2,6 \mathrm{Gal}$ affinity and lower infectivity levels for both types of cells [27]. Three strains (AEH42763, AEH42796, ADX96236) of EA lineage strains possessed $\mathrm{L}$ at the position 226, while the strains of other lineages possessed Q at the position 226. Different lineage viruses had the different amino acid at the receptor-binding sites, which suggested that they might have different host range.

Polymerase played a critical role in the adaptation of avian influenza viruses to mammalians. Avian influenza viruses have $\mathrm{E}$ at 627 position of $\mathrm{PB} 2$, whereas all human viruses (H1N1, H2N2, and $\mathrm{H} 3 \mathrm{~N} 2$ ) have $\mathrm{K}$ [28]. Additionally, the mutation E627K was reported to be responsible for host range, tissue tropism and increased virulence of avian viruses in mammals [29,30]. All of the strains of CS, ESH, and RSH lineage possessed $\mathrm{K}$ at the position 627 , while the strains of other lineage possessed $\mathrm{E}$ at the position 627. It was further revealed that PB2 genes of the CS, ESH, and RSH lineage were closely related to human influenza viruses, $\mathrm{PB} 2$ genes of the EA, $\mathrm{TR}$, and $2009 \mathrm{H}$ lineage were closely related to avian influenza viruses.

\section{Discussion}

Different host species displayed differing virus-binding receptors with preferences for either Neu5Aca2-3Gal or 
Figure 4 Phylogenetic tree of the PA genes of the H1N1 subtype swine influenza viruses. The unrooted phylogenetic trees were generated by the neighbor-joining method using MEGA 5.0 software. Bootstrap values were calculated out of 1000 replicates and only bootstrap values of $\geq 70 \%$ were shown. Different lineages were indicated by different colors.

Neu5Aca2-6Gal epitopes [24,31]. Both Neu5Aca2 -3Gal or Neu5Aca2-6Gal receptors existed in the tracheal epithelium cells in pigs, preferred by avian influenza viruses and human influenza viruses, respectively $[32,33]$ indicated that pigs could infect with swine, human, and avian viruses. Therefore, it suggested pigs could act as intermediate hosts, or mixing vessels, for the generation of genetically reassortant viruses with human pandemic potential.

Viruses sequences download from GenBank were mostly isolated in recent years. The relative strains were mainly isolated and reported in Guangdong and Shandong provinces. Most existing swine data were derived from opportunistic samples collected from diseased pigs in disparate geographical regions, not from prospective studies in defined locations [18]. Although the sampling bias might be another reason, pigs were raised in increasing numbers continually in many provinces in mainland China, especially in Guangdong and Shandong province. Meanwhile, swine influenza virus might become prevalent in the nation. To a certain extent, it showed that swine influenza virus became prevalent in mainland China in recent years.

A first study to characterize the evolution of complete genomes of influenza A H3N2, H1N1 and H1N2 isolates from Europe from 1999 to 2006, indicated that H1N1 SIVs had been evolving and might be likely to be the prevalent strain again. And more precise knowledge about the circulating strains might be help for predicting the following season strains [34]. A historical record of the genetic and antigenic evolution of swine influenza viruses in European, and described the transmission of European swine influenza viruses from pigs to other animal species and to humans, together with the factors that limit inter-species transmission [35].

As the classification of lineages to study the influenza viral ecology, epidemiology, and evolution was of great importance, so in our study, we firstly analyzed the allover H1N1 SIVs sequences in mainland China from the GenBank and integrated the information from the publicly available sequences, identified and unified all the lineages and genotypes of H1N1 SIVs in mainland China. Recently, a study has quantified the epidemiological, genetic and antigenic dynamics of swine influenza A viruses in Hong Kong using a data set of more than 650 swine influenza A viruses isolates and more 
Figure 5 Phylogenetic tree of the NP genes of the H1N1 subtype swine influenza viruses. The unrooted phylogenetic trees were generated by the neighbor-joining method using MEGA 5.0 software. Bootstrap values were calculated out of 1000 replicates and only bootstrap values of $\geq 70 \%$ were shown. Different lineages were indicated by different colors.

than 800 swine sera from 12 years of systematic surveillance in this region, supplemented with data stretching back 34 years. And their results showed that one reason for lineage change might be a competitive advantage of EA over CS and TRIG viruses [18].

Classical H1N1 swine influenza viruses, co-circulating with $\mathrm{H} 3 \mathrm{~N} 2$ swine influenza viruses, were most prevalent for a long time. However, since the Asian avian influenza virus-like $\mathrm{H} 1 \mathrm{~N} 1$ influenza viruses had been isolated from pigs in 1993 and had circulated with classical H1N1 viruses in previous studies [36-38]. In 2007-2008, European avian-like H1N1 viruses were also detected in pigs in China [39,40]. Similar to the H9N2 influenza viruses [41], the phylogenetic diversity and complexity also existed in H1N1 SIVs in mainland China. The knowledge of its diversity and complexity was still inadequate, and had not attracted much attention. Our study identified and unified all the lineages and genotypes of H1N1 subtype swine virus in mainland China, and provided the essential information supporting for further study of H1N1 subtype swine influenza viruses in Mainland China.

Influenza A viruses genetic reassortments, that might generate pandemic strains of influenza A virus, occur when two or more strains of influenza virus co-infect the same cell, especially from different host as the segmented nature of the RNA genomes [42,43]. Study has shown that reassortments between EA and triplereassortant swine viruses do occur and establish in swine as stable lineages in swine [18]. Recombinant was a process that was a frequent generation of new reassortant but had only a few survival and persistence [44]. Reassortment and antigenic change were linked [18] which has been described in North America CS viruses after the events that generated the triple-reassortant swine viruses [8]. These similar events have also been reported in human influenza [45]. Novel lineages and genotypes of H1N1 SIVs appeared in mainland China, raising the possibility of generating novel H1N1 SIVs with the potential to infect human.

Influenza virus pandemic was considered inevitable. In the early years, studies had focused on the emergence of the next pandemic in China [46-49]. China was the biggest pork producer in the world, almost all of its 50 million metric tons of production in 2010 (half of all the pork in the world) was consumed domestically. Most of 
Figure 6 Phylogenetic tree of the M genes of the H1N1 subtype swine influenza viruses. The unrooted phylogenetic trees were generated by the neighbor-joining method using MEGA 5.0 software. Bootstrap values were calculated out of 1000 replicates and only bootstrap values of $\geq 70 \%$ were shown. Different lineages were indicated by different colors.

the facilities of the pig farm in mainland China cannot provide sufficient temperature control, resulting in pigs susceptible to respiratory diseases, but it has not been given sufficient attention. Furthermore, increasing pig movements, and human, swine influenza viruses coexisting in swine herds made the swine influenza viruses diversity and offered more opportunities to generate reassortment viruses with the potential to infect humans.

Generally, lowly concerning to low pathogenic influenza viruses raise made these strains might have a greater opportunity to become widespread. As amino acid position 222 and 226 was in the receptor binding cavity, changes can potentially influence receptor binding of the influenza virus and host range. Three strains (AEH42763, AEH42796, ADX96236) of EA lineage possessed $\mathrm{L}$ at the position 226 , might had a higher affinity for sialic acid $\alpha 2$, 6-galactose (SA $\alpha 2,6 \mathrm{Gal})$ and a higher infectivity level for primary swine and human respiratory epithelial cells. The strains of other lineages possessed Q at the position 226 might had lower SA 2 2, 6Gal affinity and lower infectivity levels for both types of cells. A possible correlation of D222G substitution in HA subunit of $2009 \mathrm{H}$ viruses with severe clinical outcome was observed [50]. So strains of 2009H, CS, ESH, and RSH lineage, which possessed D222G, should be received special attention. The clinical significance was still unclear about the other substitutions at the same position, EA strains possessed E222 K. The E627K substitution was observed to enhance virulence and viral replication in mice and other mammals $[27,51,52]$. Our study suggested that H1N1 SIVs contained PB2 genes of the CS, $\mathrm{ESH}$, and RSH lineage might infect human easily.

Special attention and close supervision should be got raised on the genotypes of $2009 \mathrm{H}, \mathrm{ESH}, \mathrm{RSH}, \mathrm{CS}-\mathrm{H} 3 \mathrm{~N} 2$ and $2009 \mathrm{H}-\mathrm{EA}$, which were directly related to human influenza viruses, including genes derived from human influenza virus strains. We believed that these emerging strains would certainly have a major impact on the pigs and human public health, but we could not know specifically how it affected, it required more close monitoring.

It is well known that influenza virus genomes could escape host preexisting immunity by antigenic drift or antigenic shift, resulting in influenza outbreak in animals and even humans $[6,53,54]$. A recent study has revealed that the 2009H-like, TR-like, CS-like, and EA-like 
Figure 7 Phylogenetic tree of the NS genes of the H1N1 subtype swine influenza viruses. The unrooted phylogenetic trees were generated by the neighbor-joining method using MEGA 5.0 software. Bootstrap values were calculated out of 1000 replicates and only bootstrap values of $\geq 70 \%$ were shown. Different lineages were indicated by different colors.

viruses were co-circulating in pigs in southern China with relatively, and $2009 \mathrm{H}$-like viruses might have been maintained in pigs for a period of time and will likely become established in pigs [55]. With the evolution of swine viruses and development of pork industry, indepth and larger-scale geographic region studies on H1N1 subtype swine influenza viruses in mainland China are still required, to comprehend and monitor the variation, prevalence, transmission, potential hazard of H1N1 subtype swine influenza viruses.

\section{Conclusions}

In conclusion, our study has demonstrated that phylogenetic diversity and complexity existed in H1N1 SIVs in mainland China. Moreover, they were closely related to other subtype influenza viruses, especially human influenza viruses. Through our research, we identified and unified all lineages and genotypes of H1N1 SIVs in mainland China. Novel lineages and genotypes of H1N1 SIVs appeared in mainland China, raising the possibility of generating novel H1N1 SIVs with the potential to infect humans. We provided the essential information to support for further study and confirmation on the genetic and evolutionary characteristics of H1N1 SIVs. Close surveillance should be put into practice about novel lineages and genotypes of H1N1 SIVs in mainland China.

\section{Methods}

H1N1 subtype swine influenza virus sequences

H1N1 subtype swine influenza virus sequences used in this study were obtained from the NCBI Influenza Virus Resource Database (http://ncbi.nlm.nih.gov/genomes/ FLU/FLU.html), till December 27, 2011. Full-length only sequences were collected, containing the complete ORF (Additional file 1: Table S1). BLASTs [56] were conducted on H1N1 subtype swine influenza virus sequences to identify related reference viruses, consisting of viruses isolated from swine, avian, and human.

\section{Phylogenetic analysis}

All the around influenza virus sequences alignments were performed using the software of Clustal X [57] and the genetic distance among the representative sequences were calculated using the model of Kimura-2-Parameter 
Figure 8 Phylogenetic tree of the PB1 genes of the H1N1 subtype swine influenza viruses. The unrooted phylogenetic trees were generated by the neighbor-joining method using MEGA 5.0 software. Bootstrap values were calculated out of 1000 replicates and only bootstrap values of $\geq 70 \%$ were shown. Different lineages were indicated by different colors.

using the software MEGA 5.0 [58]. To estimate the genetic diversity and the level of gene reassortment, phylogenetic trees were constructed for each genomic segment independently. The unrooted phylogenetic trees were constructed for genomic segments using the software MEGA 5.0 with neighboring-joining method [58]. Bootstrap values were calculated out of 1000 replicates.

\section{Genotypic analysis}

Genotypic analysis of H1N1 subtype swine influenza viruses in mainland China was performed systematically for each of the eight gene segments based on the distribution of lineages in phylogenetic trees. Virus genotypes were defined by gene phylogeny. The distinct phylogenetic lineage with bootstrap support of $\geq 70 \%$ indicated a common origin. Viruses only with the classical swine (CS) lineage were designated genotype CS, and viruses with the Eurasian avian-like (EA) lineage and the 2009 human (2009H) lineage were designated genotype EA-2009H. The other genotypes were like this. Genotypes of all H1N1 subtype swine influenza viruses in mainland China analyzed were summarized in Figure 9.

\section{Ethical approval}

All of the animal slaughter experiments were conducted in accordance with the guidelines of Guangdong Province on the Review of Welfare and Ethics of Laboratory

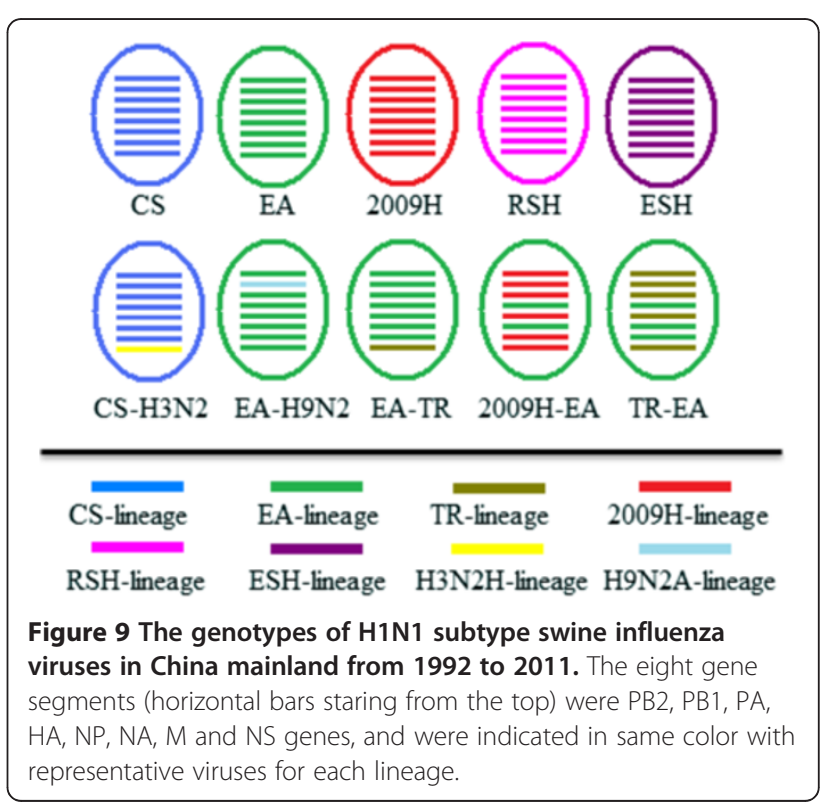


Table 2 The analysis of amino acid sequences of the HA and PB2 genes

\begin{tabular}{lllll}
\hline Lineages & Cleavage sites & \multicolumn{2}{c}{ HA } & PB2 \\
\cline { 3 - 5 } & & $\mathbf{2 2 2}$ & $\mathbf{2 2 6}$ & $\mathbf{6 2 7}$ \\
\hline $\mathrm{CS}$ & PSIQSR $\downarrow G$ & $\mathrm{G}$ & $\mathrm{Q}$ & $\mathrm{K}$ \\
\hline $\mathrm{TR}$ & $\mathrm{PSIQSR} \downarrow \mathrm{G}$ & $/$ & $/$ & $\mathrm{E}$ \\
\hline $\mathrm{EA}$ & $\mathrm{PSINQSR \downarrow G}$ & $\mathrm{E} / \mathrm{K}$ & $\mathrm{L} / \mathrm{Q}$ & $\mathrm{E}$ \\
\hline $\mathrm{ESH}$ & $\mathrm{PSIQSR} \downarrow \mathrm{G}$ & $\mathrm{G}$ & $\mathrm{Q}$ & $\mathrm{K}$ \\
\hline $\mathrm{RSH}$ & $\mathrm{PSIQSR} \downarrow \mathrm{G}$ & $\mathrm{G}$ & $\mathrm{Q}$ & $\mathrm{K}$ \\
\hline $2009 \mathrm{H}$ & $\mathrm{PSIQSR} \downarrow \mathrm{G}$ & $\mathrm{D}$ & $\mathrm{Q}$ & $\mathrm{E}$ \\
\hline
\end{tabular}

Animals approved by the Guangdong Province Administration Office of Laboratory Animals (GPAOLA). All animal procedures were conducted under the protolcol (SCAU-AEC-2010-0416) approved by the Animal Ethics Committee of South China Agricultural University.

\section{Additional file}

Additional file 1: Table S1. GenBank accession numbers of gene segments of H1N1 swine influenza viruses isolated in China mainland from 1992 to 2011

\section{Competing interests}

The authors declare that they have no competing interests.

\section{Authors' contributions}

$Y L$ and JW carried out most of the experiments and wrote the manuscript, and should be considered as first authors. QX critically revised the manuscript and the experiment design. JJ, SC, CX, JM, and YB helped with the experiment. All of the authors read and approved the final version of the manuscript.

\section{Acknowledgement}

This research was supported by the National Natural Science Foundation of China (Grant no. 31072152).

\section{Author details}

${ }^{1}$ College of Animal Science, South China Agricultural University, Guangzhou 510642, China. 'uangdong Wen's Foodstuffs Group Co. Ltd, Yunfu 527439, China. ${ }^{3}$ Department of Animal Science, Michigan State University, East Lansing, MI 48824, USA. ${ }^{4}$ State Key Laboratory of Biocontrol, College of Life Sciences, Sun Yat-Sen University, Guangzhou 510006, China.

Received: 27 March 2012 Accepted: 13 November 2012 Published: 26 November 2012

\section{References}

1. Li CK, Choi BC, Wong TW: Influenza related deaths and hospitalizations in Hong Kong: a subtropical area. Public Health 2006, 120:517-524.

2. Webster RG, Bean WJ, Gorman OT, Chambers TM, Kawaoka Y: Evolution and ecology of influenza A viruses. Microbiol Rev 1992, 56:152-179.

3. Peiris JSM, Jong MDD, Guan Y: Avian influenza virus H5N1: a threat to human health. Clin Microbiol Rev 2007, 20:243-267.

4. Fouchier RA, Schneeberger PM, Rozendaal FW, Broekman JM, Kemink SA, Munster V, Kuiken T, Rimmelzwaan GF, Schutten M, Van Doornum GJ, Koch G, Bosman A, Koopmans M, Osterhaus AD: Avian influenza A virus H7N7 associated with human conjunctivitis and a fatal case of acute respiratory distress syndrome. Proc Natl Acad Sci USA 2004, 101:1356-1361.

5. Olsen B, Munster VJ, Wallensten A, Waldenstrom J, Osterhaus AD, Fouchier RA: Global patterns of influenza A virus in wild birds. Science 2006, 312:384-388.
6. Subbaral $K$, Joseph $T$ : Scientific barriers to developing vaccines against avian influenza viruses. Nature 2007, 7:267-278.

7. Shope RE: Swine influenza III. Filtration experiments and etiology. J Exp Med 1931, 54:373-385.

8. Brown $\mid \mathrm{H}$ : The epidemiology and evolution of influenza viruses in pigs. Vet Microbiol 2000, 74:29-46.

9. Webby RJ, Swenson SL, Krauss SL, Gerrish PJ, Goyal SM, Webster RG: Evolution of swine H3N2 influenza viruses in the United States. J Virol 2000, 74:8243-8251.

10. Marozin S, Gregory V, Cameron K, Bennett M, Valette M, Aymard M, Foni E, Barigazzi G, Lin Y, Hay A: Antigenic and genetic diversity among swine influenza A H1N1 and H1N2 viruses in Europe. J Gen Virol 2002, 83:735-745.

11. Qi X, LU CP: Genetic characterization of novel reassortant H1N2 influenza A viruses isolated from pigs in southeastern China. Arch Virol 2006, 151:2289-2299.

12. Shinde V, Bridges CB, Uyeki TM, Shu B, Balish A, Xu X, Lindstrom S, Gubareva LV, Deyde V, Garten RJ, Harris M, Gerber S, Vagasky S, Smith F, Pascoe N, Martin K, Dufficy D, Ritger K, Conover C, Quinlisk P, Klimov A, Bresee JS, Finelli L: Triple-reassortant swine influenza A H1 in humans in the United States, 2005-2009. N Engl J Med 2009, 360:2616-2625.

13. Smith GJD, Bahl J, Viiaykrishna D, Zhang J, Poon LL, Chen H, Webster RG, Peiris JS, Guan Y: Dating the emergence of pandemic influenza A viruses. Proc Natl Acad Sci USA 2009, 106:11709-11712.

14. Garten RJ, Davis CT, Russell CA, Shu B, Lindstrom S, Balish A, Sessions WM, Xu X, Skepner E, Deyde V, Okomo-Adhiambo M, Gubareva L, Barnes J, Smith CB, Emery SL, Hillman MJ, Rivailler P, Smagala J, de Graaf M, Burke DF, Fouchier RA, Pappas C, Alpuche-Aranda CM, Lopez-Gatell H, Olivera H, Lopez I, Myers CA, Faix D, Blai PJ, Yu C, et al: Antigenic and genetic characteristics of swine-origin 2009 A H1N1 influenza viruses circulating in humans. Science 2009, 325:197-201.

15. Smith GJ, Vijaykrishna D, Bahl J, Lycett SJ, Worobey M, Pybus OG, Ma SK, Cheung CL, Raghwani J, Bhatt S, Peiris JS, Guan Y, Rambaut A: Origins and evolutionary genomics of the 2009 swine-origin H1N1 influenza A epidemic. Nature 2009, 459:1122-1125.

16. Pereda A, Cappuccio J, Quiroqa MA, Baumeister E, Insarralde L, Ibar M, Sanquinetti R, Cannilla ML, Franzese D, Escobar Cabrera OE, Craiq MI, Machuca A, Debenedetti RT, Zenobi C, Barral L, Balzano R, Capalbo S, Risso A, Perfumo CJ: Pandemic H1N1 2009 outbreak on pig farm, Argentina. Emerg Infect Dis 2010, 16:304-307.

17. Vijaykrishna D, Poon LL, Zhu HC, Ma SK, Li OT, Cheung CL, Smith GJ, Peiris JS, Guan Y: Reassortment of pandemic H1N1/2009 influenza A virus in swine. Science 2010, 328:1529.

18. Weingartl HM, Berhane $Y$, Hisanaga T, Neufeld J, Kehler H, Emburrt-Hyatt C, Hooper-McGreevy K, Kasloff S, Dalman B, Bystrom J, Alexandersen S, Li Y, Pasick J: Genetic and pathobiologic characterization of pandemic H1N1 2009 influenza viruses from a naturally infected swine herd. J Virol 2010, 84:2245-2256

19. Dhanasekaran V, Smith GJD, Pybus OG, Zhu HC, Bhatt S, Poon LLM, Riley S, Bahl J, Ma SK, Cheung CL, Perera RAPM, Chen HL, Shortridge KF, Webby RJ, Webster RG, Guan Y, Malik Peiris JS: Long-term evolution and transmission dynamics of swine influenza A virus. Nature 2011, 473:519-522.

20. Shortridge KF: The 1918“Spanish"flu: pearls from swine? Nat Med 1999, 5:384-385.

21. Shortridge KFC, Stuart-Harris H: An influenza epicentre? Lancet 1982, 11:812-813

22. Guo YJ, Webbster RG: Swine H1N1 Viruses Isolated from Pigs in China and Studies on the Origin of Isolates. Chinese J Exp Clin Virol 1992, 6:347-353. In Chinese, abstract in English.

23. Zhao G, Pan J, Gu X, Lu X, Li Q, Zhu J, Chen C, Duan Z, Xu Q, Wang X, Hu S, Liu W, Peng D, Liu X, Wang $X$, Liu X: Isolation and phylogenetic analysis of avian-origin European H1N1 swine influenza viruses in Jiangsu, China. Virus Genes 2012, 44:295-300.

24. Caton AJ, Brownlee GG, Yewdell JW, Gerhard W: Antigenic structure of the influenza virus A/PR/8/34 hemagglutinin H1 subtype. Cell 1982, 31:417-427

25. Matrosovich M, Tuzikov A, Bovin N, Gambaryan A, Klimov A, Castrucci MR, Donatelli I, Kawaoka Y: Early alterations of the receptor-binding properties of $\mathrm{H} 1, \mathrm{H} 2$, and $\mathrm{H} 3$ avian influenza virus hemagglutinins after their introduction into mammals. J Virol 2000, 74:8502-12. 
26. Stevens J, Blixt O, Glaser L, Taubenberger JK, Palese P, Paulson JC, Wilson IA: Glycan microarray analysis of the hemagglutinins from modern and pandemic influenza viruses reveals different receptor specificities. $J \mathrm{Mol}$ Biol 2006, 355:1143-1155.

27. Le QM, Sakai-Tagawa Y, Ozawa M, Ito M, Kawaoka Y: Selection of H5N1 influenza virus PB2 during replication in humans. J Virol 2009, 83:5278-5281.

28. Subbarao EK, London W, Murphy BR: A single amino acid in the PB2 gene of influenza A virus is a determinant of host range. J Virol 1993, 67:1761-1764.

29. Fouchier RA, Munster V, Wallensten A, Bestebroer TM, Herfst S, Smith D, Rimmelzwaan GF, Olsen B, Osterhaus AD: Characterization of a novel influenza A virus hemagglutinin subtype $\mathrm{H} 16$ obtained from blackheaded gulls. J Virol 2005, 79:2814-2822.

30. Gao Y, Zhang Y, Shinya K, Deng G, Jiang Y, Li Z, Guan Y, Tian G, Li Y, Shi J, Liu L, Zeng $X, B u Z$, Xia $X$, Kawaoko $Y$, Chen $\mathrm{H}$ : Identification of amino acids in HA and PB2 critical for the transmission of $\mathrm{H} 5 \mathrm{~N} 1$ avian influenza viruses in a mammalian host. PLOS Pathog 2009, 5:e1000709.

31. Matrosovich MN, Gambaryan AS, Teneberg S, Piskarev VE, Yamnikova SS, Lvov DK, Robertson JS, Karlsson KA: Avian influenza A viruses differ from human viruses by recognition of sialyloligosaccharides and gangliosides and by a higher conservation of the HA receptor-binding site. Virology 1977, 233:224-34

32. Ito T, Couceiro JN, Kelm S, Baum LG, Krauss S, Castrucci MR, Donatelli I, Kida H, Paulson JC, Webster RG, Kawaoka Y: Molecular basis for the generation in pigs of influenza A viruses with pandemic potential. J Virol 1998, 72:7367-7373.

33. Peiris JSM, Guan Y, Markwell D, Ghose P, Webster RG, Shortridge KF: Cocirculation of avian H9N2 and contemporary "human" H3N2 influenza A viruses in pigs in southeastern China: potential for genetic reassortment? J Virol 2001, 75:9679-9686.

34. Karoline B, Lars PN, Anders F: The evolution of human influenza A viruses from 1999to 2006: a complete genome study. Virol J 2008, 5:40-59.

35. Kuntz SG, Madec F: Genetic and Antigenic Evolution of Swine Influenza Viruses in Europe and Evaluation of Their Zoonotic Potential. Zoonoses Public Health 2009, 56:310-325.

36. Guan Y, Shortridge KF, Krauss S, Li PH, Kawaoka Y, Webster RG: Emergence of avian H1N1 influenza viruses in pigs in China. J Virol 1996, 70:8041-8046.

37. Li HY, Xin XG, Yu KZ, Yang HL, Li YB, Zhao P, Bi YZ: Cloning purification and biological characteristics of swine influenza H3N2 subtype virus isolated from China. Chin J Vet Sci 2003, 6:560-563.

38. Chen YJ, Li HY, Shen ZY, Chen HL, Yu KZ, Bi YZ: Molecular evolution of hemagglutinin gene of $\mathrm{H} 1 \mathrm{~N} 1$ subtype swine influenza viruses isolated from the mainland of China. Chin J Prev Vet Med 2005, 1:13-17.

39. Liu JH, Bi YH, Qin K, Fu GH, Yang J, Peng JS, Ma GP, Liu QF, Pu J, Tian FL: Emergence of European avian influenza virus-like H1N1 swine influenza A viruses in China. J Clin Microbiol 2009, 47:2643-2646.

40. Yu H, Zhang PC, Zhou YJ, Li GX, Pan J, Yan LP, Shi XX, Liu HL, Tong GZ: Isolation and genetic characterization of avian-like $\mathrm{H} 1 \mathrm{~N} 1$ and novel ressortant H1N2 influenza viruses from pigs in China. Biochem Biophys Res Commun 2009, 386:278-283.

41. Dong GY, Luo J, Zhang H, Wang CM, Duan MX, Deliberto TJ, Nolte DL, Ji GJ, He HX: Phylogenetic diversity and genotypical complexity of H9N2 influenza A viruses revealed by genomic sequence analysis. PLOS One 2011, 6:1-9.

42. Palese $P$, Shaw ML: Orthomxyoviridae: the viruses and their replication. In Fields Virology. 5th edition. Edited by Knipe DM, Howley PM. Philadelphia: Lippencott Williams and Wilkins; 2001. 5:1647-1689. ISBN -10: 0-7817-6060-7.

43. Landolt GA, Karasin Al, Phillips L, Olsen CW: Comparison of the pathogenesis of two genetically different $\mathrm{H} 3 \mathrm{~N} 2$ influenza $A$ viruses in pigs. J Clin Microbiol 2003, 41:1936-1941.

44. Wolfe ND, Dunavan CP, Diamond J: Origins of major human infectious diseases. Nature 2007, 447:279-283.

45. Rambaut A, Phybus OG, Nelson MI, Viboud C, Taubenberger JK, Holmes EC: The genomic and epidemiological dynamics of human influenza $A$ virus. Nature 2008, 453:615-619.

46. Lin YP, Shu LL, Wright S, Bean WJ, Sharp GB, Shortridge KF, Webster RG: Analysis of the influenza virus gene pool of avian species from southern China. Virology 1994, 198:557-566.

47. Shortridge KF: The next pandemic influenza virus? Lancet 1995, 346:1210-1212.
48. Shu LL, Zhou NN, Sharp GB, He SQ, Zhang TJ, Zou WW, Webster RG: An epidemiological study of influenza viruses among Chinese farm families with household ducks and pigs. Epidemiol Infect 1996, 117:179-88.

49. Shu LL, Lin YP, Wright SM, Shortridge KF, Webster RG: Evidence for interspecies transmission and reassortment of influenza $A$ viruses in pigs in southern China. Virology 1994, 202:825-833.

50. Kilander A, Rykkvin R, Dudman SG, Hungnes O: Observed association between the HA1 mutation D222G in the 2009 pandemic influenza AH1N1 virus and severe clinical outcome, Norway 2009-2010. Eurosurveillance 2010, 15: pii = 19498.

51. Manzoor R, Sakoda Y, Nomura N, Tsuda Y, Ozaki H, Okamatsu M, Kida H: $\mathrm{PB} 2$ protein of a highly pathogenic avian influenza virus strain $\mathrm{A} /$ chicken/Yamaguchi/7/2004H5N1 determines its replication potential in pigs. J Virol 2009, 83:1572-1578.

52. Mase M, Tanimura N, Imada T, Okamatsu M, Tsukamoto K, Yamaguchi S: Recent $\mathrm{H} 5 \mathrm{~N} 1$ avian influenza $\mathrm{A}$ virus increases rapidly in virulence to mice after a single passage in mice. J Gen Virol 2006, 87:3655-3659.

53. Chi XS, Bolar TV, Zhao P, Tam JS, Rappaport R, Cheng SM: Molecular evolution of human influenza $\mathrm{A} / \mathrm{H} 3 \mathrm{~N} 2$ virus in Asia and Europe from 2001 to 2003. J Clin Microbiol 2005, 43:6130-6132.

54. Potter CW: A history of influenza. J Appl Microbiol 2001, 91:572-579.

55. Zhu HC, Zhou BP, Fan XH, Lam TTY, Wang J, Chen A, Chen XC, Chen HL, Webster RG, Webby R, Peiris JSM, Smith DK, Guan Y: Novel reassortment of Eurasian Avian-like and Pandemic/2009 Influenza viruses in swine: infectious potential for humans. J Virol 2011, 85:10432-10439.

56. Altschul SF, Madden TL, Schaffer AA, Zhang J, Zhang Z, Miller W, Lipman DJ: Gapped BLAST and PSI-BLAST: a new generation of protein database search programs. Nucleic Acids Res 1997, 25:3389-3402.

57. Larkin MA, Blackshields G, Brown NP, Chenna R, McGettigan PA, McWilliam $H$, Valentin F, Wallace IM, Wilm A, Lopez R, Thompson JD, Gibson TL, Hiqqins DG: Clustal W and Clustal X version 2.0. Bioinformatics 2007, 23:2947-2948.

58. Tamura K, Peterson D, Peterson N, Stecher G, Nei M, Kumar S: MEGA5: molecular evolutionary genetics analysis using maximum likelihood, evolutionary distance, and maximum parsimony methods. Mol Biol Evol 2011, 28:2731-2740.

doi:10.1186/1743-422X-9-289

Cite this article as: Liu et al:: Phylogenetic diversity and genotypic complexity of $\mathrm{H} 1 \mathrm{~N} 1$ subtype swine influenza viruses isolated in Mainland China. Virology Journal 2012 9:289.

\section{Submit your next manuscript to BioMed Central and take full advantage of:}

- Convenient online submission

- Thorough peer review

- No space constraints or color figure charges

- Immediate publication on acceptance

- Inclusion in PubMed, CAS, Scopus and Google Scholar

- Research which is freely available for redistribution 